\title{
"The thing about animals is they are not judgemental": Stories and images from formerly incarcerated women about their relationships with companion animals
}

Michele Jarldorn, University of South Australia

\begin{abstract}
INTRODUCTION: The data presented in this research brief are drawn from a project which asked 12 former prisoners what they thought outsiders should know about imprisonment and release. One of the themes arising from the data suggested that, rather than participating in a mandated programme or professionally delivered intervention, the reasons for successfully staying out of prison were based on relationships and connections. Sometimes these relationships were with family, community, a specific worker or group and, for six of the women, with companion animals. It was a combination of these relationships which helped the participants find their own pathways to staying in the community and, eventually, out of the criminal justice system.
\end{abstract}

APPROACH: Data were created using Photovoice, an arts-based, qualitative, participatory action research method where participants take photographs and then use those images to help tell their story. Participants were invited to talk about anything they saw as important for outsiders to know about their experiences of imprisonment and release. Unexpectedly, six of the women chose to speak about the importance of their relationship with companion animals.

FINDINGS: The data presented here show the value that women in this project placed on their relationships with companion animals. More broadly, their data point to the importance of having non-judgemental relationships and the benefits of being able to 'give back'.

CONCLUSION: The unexpected findings presented in this research brief suggest that social workers must take into consideration all relationships criminalised women have, not just those with other humans.

KEYWORDS: Photovoice; companion animals; formerly incarcerated women
In 2018, I completed a research project which used the qualitative, participatory, arts-based research method Photovoice, to learn about the post-release experiences of 12 people who had all spent time in South Australian prisons (Jarldorn, 2018). Armed with a camera, participants were asked to take photographs and create narratives supporting the images to respond to the following research question: "If you had fifteen minutes with a policy maker or politician, what would you want to tell them about your experience?" Given this freedom to speak candidly meant that I heard about families,
AOTEAROA

NEW ZEALAND SOCIAL WORK 32(4), 69-76.

CORRESPONDENCE TO: Michele Jarldorn Michele.jarldorn@unisa. edu.au 
communities, relationships, addiction, domestic violence, lack of housing and employment. The overarching theme, though, was the interpersonal and structural violence they saw and experienced created by the prison system (Jarldorn, 2019).

One of the key things I learned from the research was the long-term consequences of imprisonment, where "the pain inflicted by prisons is carried with former prisoners as they return to the community" (Jarldorn, 2019, p. 328). As I have explained elsewhere, this led me to contend that the arguments supporting the abolition of prisons fit within the purpose of social work, and to question the place and purpose of prisons in responding to social problems. Mansfield's discussion of abolition clarifies this position:

By relying on prisons, we are effectively abandoning our most vulnerable and challenged people, people who we struggle to include, and people who struggle to belong. But we cannot solve problems of connection by placing people behind walls, away from our communities. By continuing to rely unthinkingly on prison and punishment as responses to social problems, we are missing vital opportunities and resources-time, energy, money and

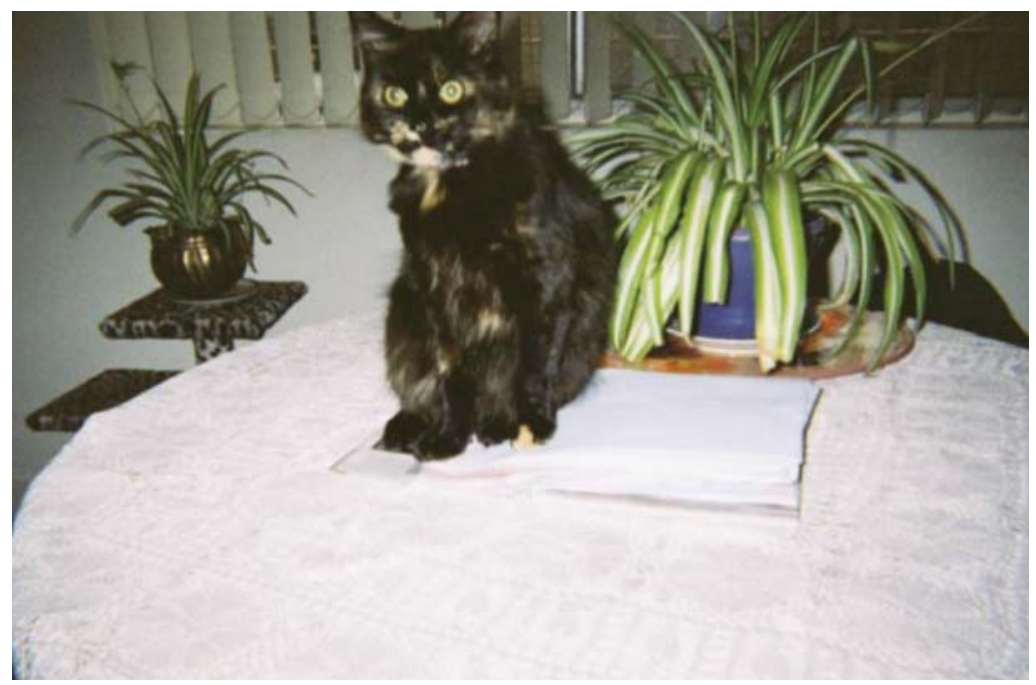

Figure 1. My Darling (Gidget). attention-to build stronger communities of connection, to heal the harms caused by imprisonment, and to address the issues that led to it in the first place. (2018, para. 1)

My aim in this project was to respect each participant's stories and texts on their own grounds rather than ranking them in some order or hierarchy. Hence, this research brief focusses on the data created by six of the women who chose to talk about the importance of companion animals in their lives. At the time of data collection (20142015), all but one participant had been out of prison for a year or more. To my knowledge, each participant discussed in this paper is still living in the community in 2020, making them a unique group of successful prison leavers, especially given the high proportion of people who return to prison within two years of their release (Baldry, 2010).

Their data suggest that-rather than participating in a mandated programme, professional intervention or through close surveillance- one of the core reasons for participants successfully staying out of prison was having positive and nurturing relationships and connections. This was usually a combination of relationships with family, community, a specific worker or group or, as shown here, with companion animals. These positive relationships helped participants find their own pathways to staying in the community and, for some, leaving the criminal justice system altogether.

The images and narratives in this paper were created by Gidget, Kate, Feeney, Georgia, Joy and Stella. All names used here-of the women and their companion animals-are pseudonyms chosen by the women. Ethics approval was granted in 2013 (\#6255) by Flinders University Social and Behavioural Sciences Ethics Committee. Participants were interviewed individually, over the course of about eight months.

Gidget was the first participant who spoke about companion animals. At first, 
I thought maybe Gidget had run out of things to say, but over and over, women in the project chose to share with me the contributions companion animals had made to their success in remaining free. Gidget was released from prison into an isolating environment, describing here how getting a kitten gave her more than just company.

When I got out of prison I was on my own. I had no real friend support because my only friends and social networks were involved in areas that I weren't allowed to associate with anymore. I was really worried about my mental state being on my own for so long. It took me while to get a cat because I didn't know how I'd handle the responsibility. Then when I got her, she taught me commitment, loyalty and she taught me to love again because I hadn't had that for so long.

I had just spent years in a place where I couldn't even smile at the wrong person, it could come back at me. Now I've got this wonderful animal who is expressing love for nothing, you know, just for a meal. It doesn't matter what I do, she still loves me the next day.

Gidget's narrative shows the post-release impact of surviving prison. In prison, many women learn to desensitise as a coping method because showing emotions can make you a target for other prisoners and correctional officers (Kilroy, 2013, p. 287), putting them at risk of a stint in segregation or being medicated (Pinnuck, 1998). This in-prison survival strategy becomes problematic post-release, making it difficult to create, build and sustain new friendships and connections. Regaining the ability to trust through a companion animal is a relatively safe way of redeveloping sensitivity.

I next met Kate. Although she only wanted a dog (pictured), Kate also adopted a cat because the two were inseparable in the animal shelter where she volunteers. In another image and narrative, Kate explained how hard it was for her to find paid employment because of her criminal record, despite being a model prisoner and a parolee who never breached her release conditions. Volunteering gave Kate the means to make amends or to "pay back," a theme most participants discussed. Empathic to their plight as being unwanted, institutionalised and being "locked away," Kate spoke about the unconditional love she gets from being with her dog.

I feel so close to my dog because he has come from a shelter. That makes me feel like he has been in an institution too, he was abandoned. It is nice to give him freedom, to live in a nice home. He is very affectionate; he welcomes you every time with a tail wagging and eyes bright. The thing about animals is they are not judgemental; they don't know what you've done. They live in the minute and are very entertaining because of that. I really enjoy taking him for a walk every day, because it is lovely to see him running free and enjoying every moment of it. He gets me out which is really good for me.

For Kate, her dog is her friend and her inspiration to get regular exercise. She revels in seeing him enjoy freedom; Billy embodies what it is to be free.

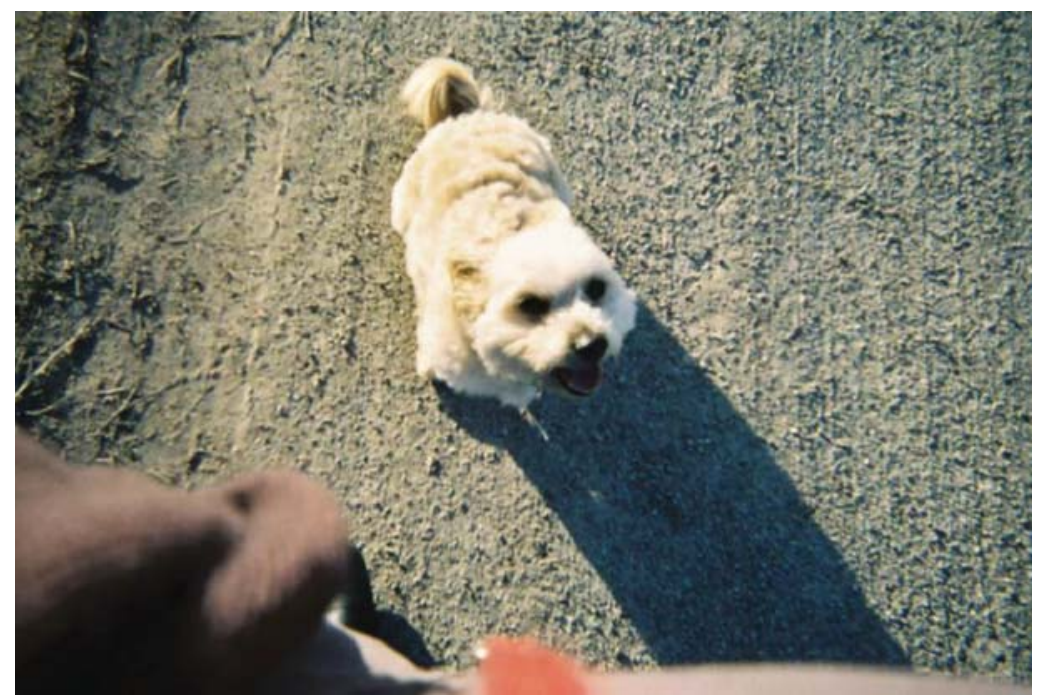

Figure 2. My best friend Billy (Kate). 
Feeney, Georgia and Joy had companion animals before going to prison. Each of them spoke of feeling privileged that their dogs were properly taken care of while they were incarcerated. They were lucky as many people lose their companion animals when they go to prison-as was the case with another participant, Ruby, who submitted a drawing of the two cats she relinquished.

Georgia and Feeney spoke about the difficulty of being separated from their companion animals. Not only did they miss them deeply, but they also recognised the impact that their imprisonment had on them. Their grief at being separated from their companion animals was very real, despite it rarely being recognised or acknowledged (Thomas, 2014). Thinking about the impact of her imprisonment upon her dog, Feeney told me:

I just love my dog to bits; he went through it all with me. Before I went to prison, I was in a really depressed state, not knowing what was going to happen. I withdrew from the world and isolated myself. Costa was just always there for me. I would cry all the time and

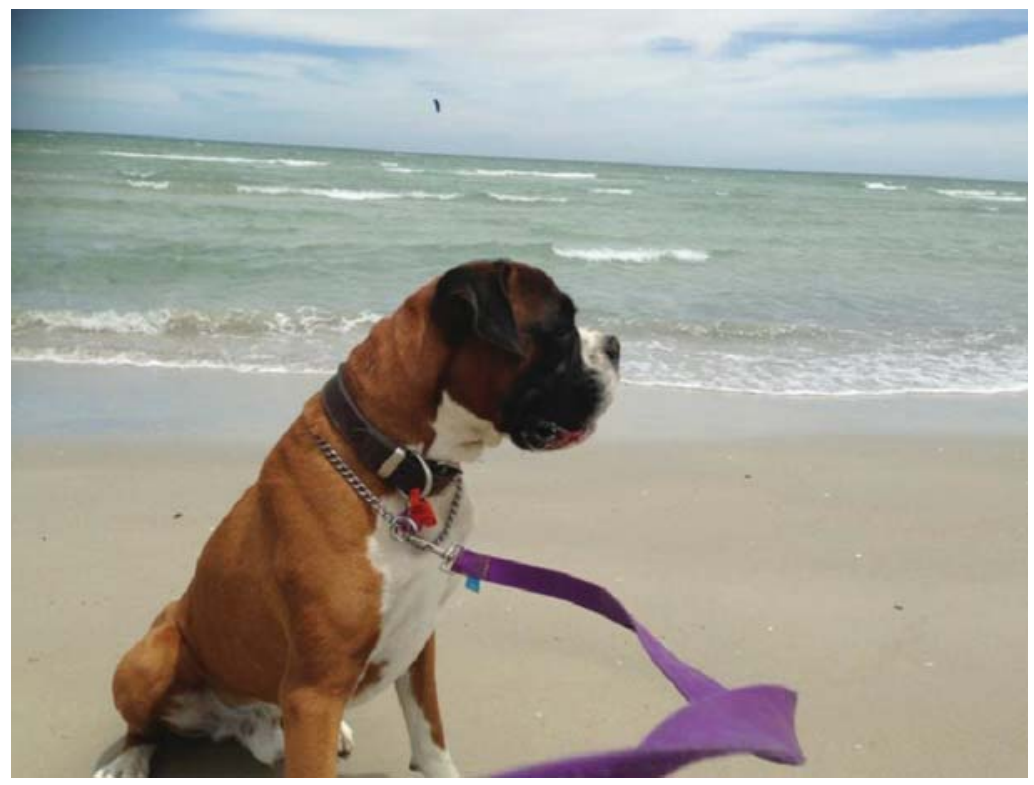

Figure 3. My dog Costa (Feeney). he would come and put his head in my lap. He could sense how I was feeling. I don't know what I would have done without him. When I went to prison, I used to wonder what Costa was thinking, perhaps he thought I was dead. I got to come home for a few hours a month before I was released. He was so excited, but then I had to go again. It must have gotten so confusing for him. I mean I could see my partner when he came to visit, but not my dog. I missed him terribly.

For Georgia, having no children meant that her relationship with her dog plays a significant role in the construction of her sense of family and therefore her identity. Georgia acknowledged the importance of being loved "non-judgementally" recognising that many women miss their companion animals terribly while they are in prison. She said:

He's my everything. He just warms your heart and makes you think everything is OK, no judgement whatsoever. Seeing him for the first time after two years, he was just so excited, just as I was. I used to talk to him over the phone from prison. He didn't eat for months after I went away, he just laid by my bedroom door waiting for me.

I'd like to have women who are close to their animals to have an animal day, so they could come in and spend some time every few months, so you've got that bonding time, like they do for kids. I feel that animals are just as important as kids in my life.

As Fook (2014) points out, many women have important and significant relationships with their companion animals, considering them to be family members and friendsrarely does a woman report "owning" a pet (p. 25). The fact that, when a person is taken into custody, little consideration is given to their pets, is an important issue which needs to be addressed. 


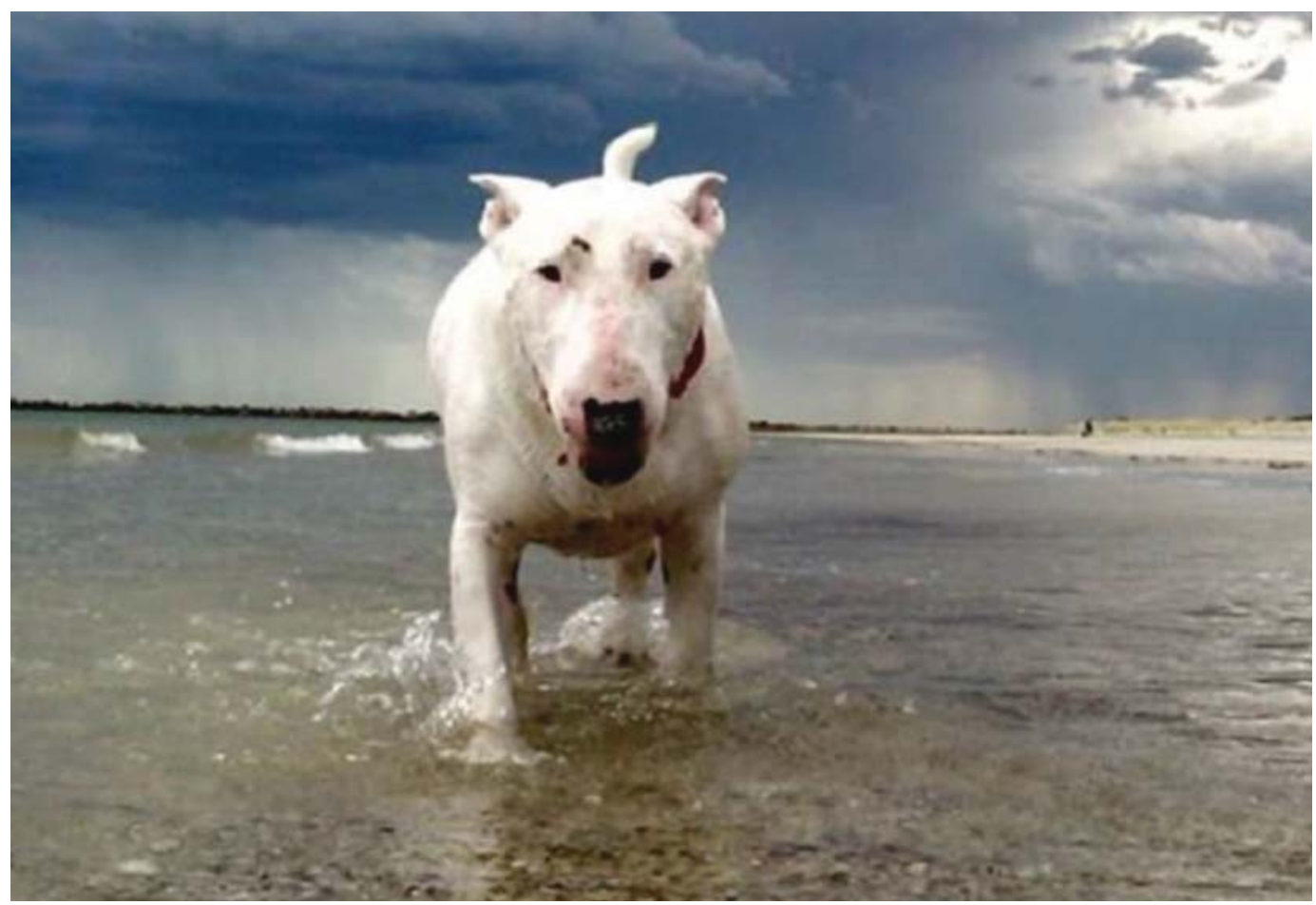

Figure 4. My dog (Georgia).

When Joy was released from prison, she was isolated, living by herself in postrelease housing. Joy believes that if it wasn't for her dog, and the associated caring responsibilities, she may not have been so successful in staying out of prison. Joy credits her dog with helping her manage her addiction, saying that when she experiences cravings, she puts her dog on a lead and they head out for a walk.

I was really lucky that I had someone to look after my dog while I was in prison, so when I got out, I still had her. Now that am out, I feel like she has got my back, she's looking out for me and protecting me. She is my best mate, especially when I was on Home Detention. I don't know what I would do without her. I had to spend a lot of time on my own and was totally isolated. I was allowed some time to walk her every day. If I didn't have her, I wouldn't have felt like doing anything. Life would have been crap without her. She makes me feel safe and has helped me survive.
This strategy used by Joy to manage triggers and cravings demonstrates an effective use of the behavioural aspect of coping with cravings, known in the alcohol and other drugs sector as the 3Ds-delay, distract and decide (see Australian Government Department of Health, 2003). Without her dog, Joy may not have been so successful in staying out of prison.

My final interview was with Stella. In her community work, Stella volunteers many hours per week supporting women who leave prison. At the time of the interview she had also been volunteering for an animal shelter which aims to rehouse "risky and at risk" dogs. Often, the dogs have been mistreated or have behavioural problems which prevent them from being adopted, placing them at risk of being euthanised. Stella takes these dogs into her home, "transforming" their behaviour, beginning by getting to know each one individually, seeing their strengths and working on their ability to socialise with other dogs and humans. Stella uses 


\section{QUALITATIVE RESEARCH}

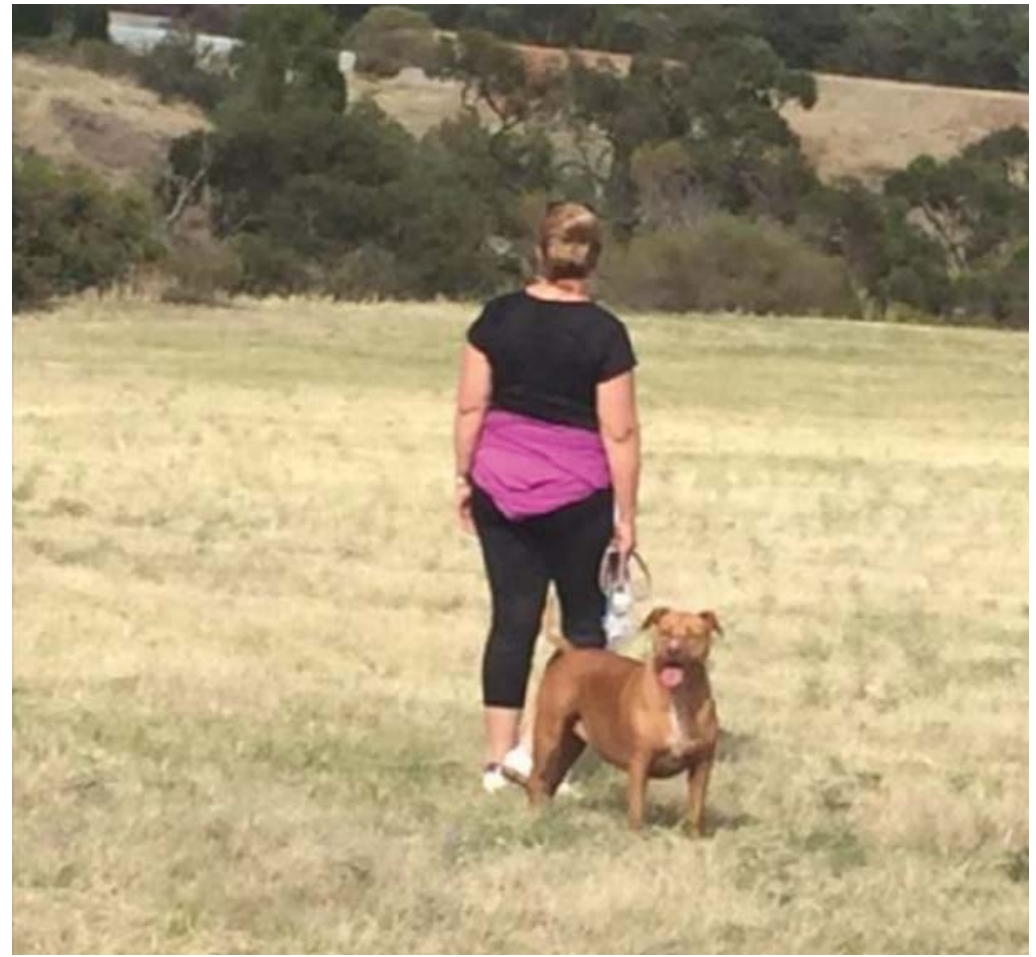

Figure 5. She's got my back (Joy).

long distance, early morning running to help maintain her sobriety (for more see Jarldorn, 2019) and spoke of her

"big picture dreams," telling me:

I have my own dogs and I foster and rehabilitate dogs for SA Dog Rescue. I take the dogs with me when I run-you try and stop them from coming! I get the difficult ones that have been dumped, usually because of their behavioural issues. They are full of pent up energy. Running drains that very quickly. I love finding out the nature of each different $\mathrm{dog}$, finding out who they really are without all that pent-up stuff and baggage-when you run 4 hours you get to that point very quickly.

Rehabilitating dogs has taught me so much about myself. It doesn't matter what you were 20 years ago to a dog, what matters is the energy that you are projecting to that dog at that very minute. I would have 50 dogs if I could. One day
I would love to open up a dog rescue centre and hire and teach other women ex-prisoners to rehabilitate dogs, because you can't rehabilitate a dog until you are balanced yourself.

As Stella suggests, a lot can be learned from caring for an animal-equally, a lot can be gained by being cared about by them. Stella devotes a great deal of her time and energy to these dogs in recognition of what dogs have done for her. As she explained, at a time when her physical health was in jeopardy, it was the unconditional love of dogs that helped her to begin to see the beauty in the simple things in life. Stella said:

After I had gotten sick my dogs taught me how to live again. They taught me how to appreciate the grass and the sun, the sky, a bit of mud on the ground, just the simple stuff. I thought I was going to die; I was so sick. My dogs were with me the whole time. Now when I take them out and feel the grass under my feet and feel the sun on my skin, I think, "Wow, I'm alive." If I can save a dog's life, it means the world to me because they saved my life. I want to make the world a better place.

The idea that the world would be a better place if the relationships between humans and companion animals were respected is supported by Hanrahan (2011, p. 278), who writes:

No matter how many ways the pie is divided, human well-being will not achieve or approximate fullness until it is understood within the context of the quality of human-animal bonds, and linked to the welfare of other animals and to ecological sustainability within nature. No matter how many subject positions a person is understood to inhabit at the intersecting cross-roads of difference and sameness, we compromise our integrity by virtue of discriminating against otherthan-human life as long as the human being remains at the conceptual center of the universe. 


\section{Discussion}

There has been a growing interest in social work research and practice about the relationship between humans and companion animals (see, for example, Fook, 2014; Risley-Curtiss, 2010; Taylor, Fraser, Signal, \& Prentice, 2016). Compared to people who do not have pets, people who live with companion animals tend to be more active, have better mental and physical health and usually feel a greater sense of security from having them around (Fitzgerald, 2007). For women who leave prison, and especially for those who have experienced violent and abusive relationships, not trusting others is a safety mechanism, a way to protect themselves from further abuse. Having a bond with a companion animal can facilitate women's ability to trust and love (Fook, 2014). Fook argues that social work researchers must "keep up with the challenge of researching what is important in people's everyday lives" (Fook, 2014, p. 29) and, as Fook and others (Fitzgerald, 2007; Taylor, 2013) argue, the human/companion animal relationship is important to many women.

Before rushing to devise animal-assisted interventions, it is timely to think about some of the challenges associated with intentionally connecting people with animals, especially with respect towards the professional adage of "do no harm." For example, a recent documentary, Prisoners and Pups (Almond, 2017), followed a small group of women involved in the Greyhound Adoption Program run inside the Adelaide Women's Prison. While a beautiful film showing the value of people in prison being given the opportunity to "give back," peppered throughout the film are layers of loss and grief as women are separated from the dogs they were assigned through either the dog being adopted or the woman being released.

Having ex-prisoners volunteer in animal shelters as Kate did, or rehabilitate relinquished animals as Stella described, may be useful in providing ways to build social connections and to forge reciprocal supportive relationships, but this must be considered with a note of caution. Despite the potential for pleasure, reward and connection through volunteering at an animal shelter, it is also an environment that can be emotionally and physically demanding, where workers and volunteers experience high rates of compassion fatigue and burnout (Taylor, 2013). Further, the associated costs of keeping a companion animal are high and owning any pet can prevent entry into the rental housing market-a market already largely inaccessible to former prisoners (Baldry, 2010), effectively excluding a significant number of people from the benefits of sharing their lives with companion animals.

Challenging the cultural assumption of human superiority, relationships between women and their companion animals can be powerful and hold as much, if not more, meaning as their relationships with intimate partners (Risley-Curtiss, 2010). The relationship between humans and companion animals can enhance the quality of people's lives (Bould, Bigby, Bennett, \& Howell, 2018) and as Stella and Kate's narratives showed, humans can enhance the lives of companion animals. These reciprocal "caring" relationships are rewarded with an unconditional alliance, which for some former prisoners may be the only positive, reciprocal relationship they have. As Faver (2009) suggests, these relationships can be thought of on a spiritual level:

It is important for social workers to understand the spiritual dimension of humans' relationships with animals for two reasons. First, many people are drawn to animals as sources of spiritual guidance, healing, and companionship. Thus, social workers should be prepared to support clients' spiritual journeys by affirming their spiritual bond with animals. Second, lessons learned through the relationships with animals can facilitate social workers' professional 
development as well as their own and their clients' spiritual development. (pp. 364-365)

This research brief has shown the importance that criminalised women place on their relationships with companion animals. This knowledge suggests that time spent by social workers in helping keep these relationships intact is time well spent and may help support criminalised women remaining in the community post-release from prison.

Accepted 22 August 2020

Published 15 December 2020

\section{References}

Almond, S. (Director). (2017). Prisoners and pups [Motion picture]. Cocoon Films.

Australian Government Department of Health. (2003). A brief cognitive behavioural intervention for regular amphetamine users: A treatment guide. Retrieved from https://www1.health.gov.au/internet/publications/ publishing.nsf/Content/drugtreat-pubs-cogamphtoc drugtreat-pubs-cogamph-3 drugtreat-pubscogamph-3-2 drugtreat-pubs-cogamph-3-2-4

Baldry, E. (2010). Women in transition: From prison to... Current Issues in Criminal Justice, 22(1), 253-268.

Bould, E., Bigby, C., Bennett, P., \& Howell, T. (2018). "More people talk to you when you have a dog": Dogs as catalysts for social inclusion of people with intellectual disabilities. Journal of Intellectual Disability Research, 62(10), 833-841.

Faver, C. (2009). Seeking our place in the web of life: Animals and human spirituality. Journal of Religion \& Spirituality in Social Work: Social Thought, 28, 362-378.

Fitzgerald, A. (2007). "They gave me a reason to live": The protective effects of companion animals on the suicidality of abused women. Humanity \& Society, 31, 355-378.

Fook, J. (2014). The meaning of animals in women's lives: The importance of the "domestic" realm to social work. In T. Ryan (Ed.), Animals in social work: Why and how they matter (pp. 18-31). Palgrave Macmillan.

Hanrahan, C. (2011). Challenging anthropocentricism in social work through ethics and spirituality: Lessons from studies in human-animal bonds. Journal of Religion \& Spirituality in Social Work: Social Thought, 30(3), 272-293.

Jarldorn, M. (2018). Radically rethinking imprisonment: $A$ Photovoice exploration of life in and after prison in South Australia (Unpublished doctoral dissertation). Flinders University, Adelaide, SA.

Jarldorn, M. (2019). Radically rethinking social work in the criminal (in)justice system in Australia. Affilia: Journal of Women and Social Work, 35(3), 327-343.

Kilroy, D. (2013). Sisters inside: Speaking out against criminal injustice. In J. Sudbury (Ed.), Global lockdown: Race, gender and the prison-industrial complex (pp. 285-293). Routledge.
Mansfield, M. (2018). What is abolitionist feminism, and why does it matter? The Progressive Policy Think Tank. Retrieved from https://www.ippr.org/ juncture-item/what-is-abolitionist-feminism-and-whydoes-it-matter\#: :text=Abolitionist\%20Feminism\%20 invites\%20us\%20to,gender\%2C\%20race $\% 20$ and $\% 20$ economic\%20justice.

Pinnuck, F. (1998). The medication of prisoners: A cause for concern. Just Policy, 12, 13-19.

Risley-Curtiss, C. (2010). Social work practitioners and the human-companion animal bond: A national study. Social Work, 55(1), 38-48.

Taylor, N. (2013). Humans, animals and society: An introduction to human-animal studies. Lantern Books.

Taylor, N., Fraser, H., Signal, T., \& Prentice, K. (2016). Social work, animal-assisted therapies and ethical considerations: A program example from central Queensland. British Journal of Social Work, 46(1), 135-152.

Thomas, A. (2014). Liquid love: Grief, loss, animal companions and the social worker. In T. Ryan (Ed.), Animals in social work: Why and how they matter (pp. 199-214). Palgrave Macmillan. 